\title{
A STUDY ON PREVALENCE OF ANXIETY AMONG COLLEGE GOING GIRLS AND ITS IMPACT ON THEIR ACADEMIC PERFORMANCE
}

\author{
DR. NEETU SINGH
}

Assistant professor, Nitishwar Mahavidyalaya, BRA Bihar University, Bihar, India

\begin{abstract}
Present study "A study on prevalence of anxiety among college going girls and its impact on their academic performance" was conducted in Ambedkar Nagar district. A scale of Dr. D.N. Srivastava and Dr. Govind Tiwari was used. The survey involves 60 students of B.A and B.Sc stream. This study revealed that students suffer from high levels of anxiety. The study also revealed that B.Sc. students had high levels of anxiety as compared to B.A students. Many girls in both streams (B.A and B.Sc.) had similar high levels of anxiety.

KEYWORDS: Impact on Their Academic Performance
\end{abstract}

Received: Feb 19, 2021; Accepted: Mar 01, 2021; Published: Jun 30, 2021; Paper Id.: IJEEFUSJUN20214

\section{INTRODUCTION}

A small amount Anxiety is common in day-to-day lives. To a certain situation, it is quite common, but hard anxiety can be excruciating. At present time families suffers from lots of problem in their lives due to nuclear families, modernization, lack of family support system and loss of Indian joint family structure. This leads to stress, depression, broken family and anxiety. It is very difficult for the children to maintain a balance between family and college life. Because of these problems student's academic performance was affected and academic anxiety can become more detrimental over time. As a students' academic performance is affected, students lose their confidence and self-esteem. In severe cases, it leads to suicide and severe mental problems. The heavy burden of exams, college projects, achieving good grades and family pressure leads to heavy anxiety which affects their performance in college. Excessive anxiety leads to severe stress which was not easily coped up by students.

Due to Examination phobia, their performance in exams is affected, which leads to stomach pain, nausea, vomiting or headache. Sometimes students feel shaky, sweaty, nervous, worry as well as trembling, heart palpitations and the throat being dry .in some situations it leads to heart attack and mental imbalance.

It was also seen that Anxiety management was different in both genders. During exams or in their social circle, girls are more stressed as compared to boys. Boys are less concerned for their grades and friends circle prestige. Boys give more importance to their relationship instead of grade and status but it was different for girls. Girls were more conscious about their status and exam grades.

It is very important for the teachers and guardians to take effective measures to protect their students and children from anxiety and stress. They develop a positive and strong relationship so that students/children's feel free to 
share whatever they had in their mind during examinations.

\section{METHODOLOGY}

The sample for the study was comprised of 60 boys (30 from art stream and 30 from science stream) between the ages of 18 22 years, belonging to lower socio-economic status. Students list was prepared from college records. From these lists, a sample of 60 adolescent boys was randomly selected.

- The age of the respondents between 18 to 22 years.

- Respondents who belonged to low socio-economic status.

- The respondents were staying with their parents.

- Respondents were from Akbarpur .

\section{Tools for Data Collection}

\section{Manifest Anxiety Scales}

Manifest anxiety scale by Dr.N Shrivastav and Dr.Govimal Tiwari was used to assess the prevalence anxiety levels.

The questionnaire was given to students. The purpose of the study was explained. The scale was administered to assess the anxiety level of the boys and girls. The proforma consists of 100 items.

Administration- There is no fixed time limit. However, it takes merely half an hour to complete it.

Scoring-According to this, all positive items answered positively and receive score 1 whereas all negative item answered negatively receive zero score.

Table 1

\begin{tabular}{|c|l|}
\hline Raw Scores & Interpretation \\
\hline $00-33$ & Low \\
\hline $34-66$ & moderate \\
\hline $67-100$ & High \\
\hline
\end{tabular}

\section{Collection of Data}

The investigator contacted the selected respondents in Bindeshwari P.G.College Akbarpur, Ambedkar Nagar district. Proforma was given to each student who were requested to fill in the correct information on the basis of their own analysis. Its the researcher's responsibility to make all information confidential and use it for only thesis purposes.

\section{RESULTS AND DISCUSSION}

\section{A. Percentage Allotment of B.Sc. Stream Respondents According to their Levels of Anxiety}

According to some research, observation it was concluded that the student's anxiety was very common during the examination. Sometimes it affects their performance during an examination and students achieve a low grade, which makes them unachieved and shy in front of other students. 
Table 2: Percentage Allotment of B.Sc. Stream Respondents According to their Levels of Anxiety. (n=30)

\begin{tabular}{|l|c|c|}
\hline \multicolumn{3}{|c|}{ Distribution of B.Sc. Respondents According to Level of Anxiety. } \\
\hline Categories & $\mathbf{f}$ & \% \\
\hline Low & 1 & 3.33 \\
\hline Moderate & 17 & 56.67 \\
\hline High & 12 & 40 \\
\hline
\end{tabular}

From the above table, results indicate that among majority of students had moderate (56.67\%) level of anxiety. Result also reveals that 40 per cent boys had high level of anxiety whereas 3.33 per cent boys had low level anxiety. B) Assessment of prevalence of anxiety among B.A students.

Data from the above table reveals that majority of boys studied in B.A had moderate (70\%) level of anxiety. It was also observed that only 13.33 per cent boys had high level of anxiety whereas 16.67 per cent boys had low level of anxiety.

Table 3: Percentage Distribution of B.A. Stream Respondents According to Level of Anxiety. (n=30)

\begin{tabular}{|l|c|c|}
\hline \multicolumn{3}{|c|}{ Distribution of B.A respondents according to level of anxiety. } \\
\hline Categories & f & \% \\
\hline Low & $\mathbf{5}$ & $\mathbf{1 6 . 6 7}$ \\
\hline Moderate & $\mathbf{2 1}$ & $\mathbf{7 0}$ \\
\hline High & $\mathbf{4}$ & $\mathbf{1 3 . 3 3}$ \\
\hline
\end{tabular}

\section{c) Comparison between B.A and B.Sc. Stream Students According to their Levels of Anxiety}

The data in above table shows that 70 per cent boys studied in B.A had moderate level of anxiety, whereas among B.Sc. students 56.67 per cent boys had moderate level of anxiety. Data also reveals that 40per cent of B.Sc. students had high level of anxiety, whereas only 13.33 per cent of B.A boys had high level of anxiety. The table also shows that only 3.33 per cent of B.Sc. Students and 16.67 per cent B.A boys had low level of anxiety.

Table 4: Comparison between B.A and B.Sc. Students According to Level of Anxiety. (n=60)

\begin{tabular}{|l|c|c|}
\hline \multicolumn{3}{|c|}{ Comparison between B.A and B.Sc. Students According to Level of Anxiety } \\
\hline Categories & B.A & B.Sc. \\
\hline Low & 16.67 & 3.33 \\
\hline Moderate & 70 & 56.67 \\
\hline High & 13.33 & 40 \\
\hline
\end{tabular}




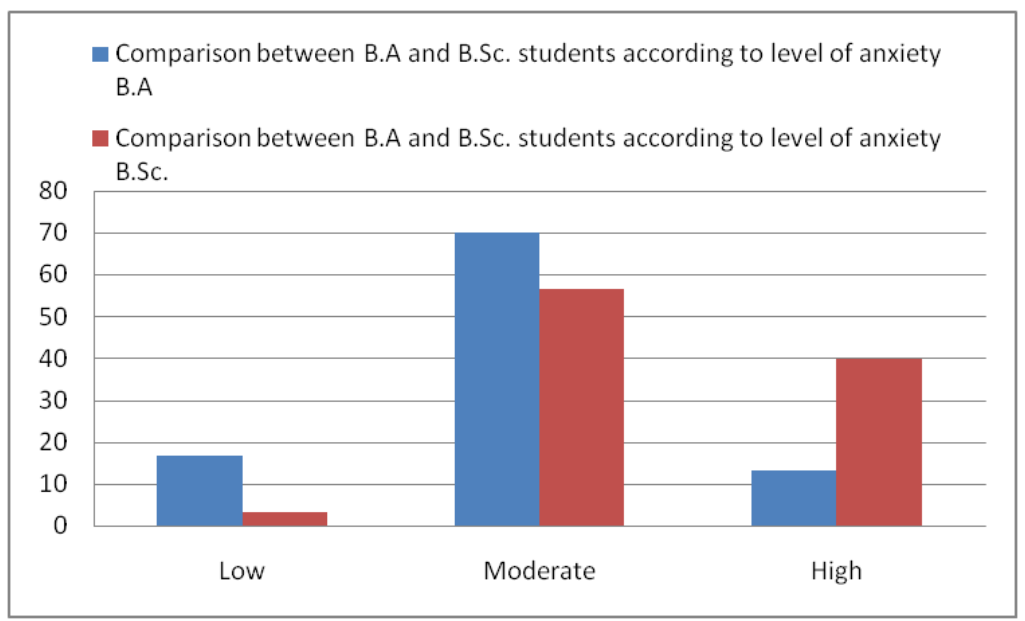

Figure 1

\section{Assessment of Prevalence Level of Anxiety among Overall Boys Studied in B.A and B.Sc}

Comparison of anxiety among overall boys studied in both B.A and B.Sc. shows that more than half of boys had moderate (63.34\%) level of anxiety. It was also observed that 26.67per cent students had high level of anxiety and 10 per cent students had lower anxiety.

Table 5: Overall Percentage Allotments of Boys on the basis of their Anxiety Extent

\begin{tabular}{|l|c|c|}
\hline \multicolumn{3}{|c|}{ Overall Percentage Distribution of Boys According to Level of Anxiety. } \\
\hline Categories & f & \% \\
\hline Low & 6 & 10 \\
\hline Moderate & 38 & 63.34 \\
\hline High & 16 & 26.67 \\
\hline
\end{tabular}

\section{Overall percentage distribution of boys according to level of anxiety.}

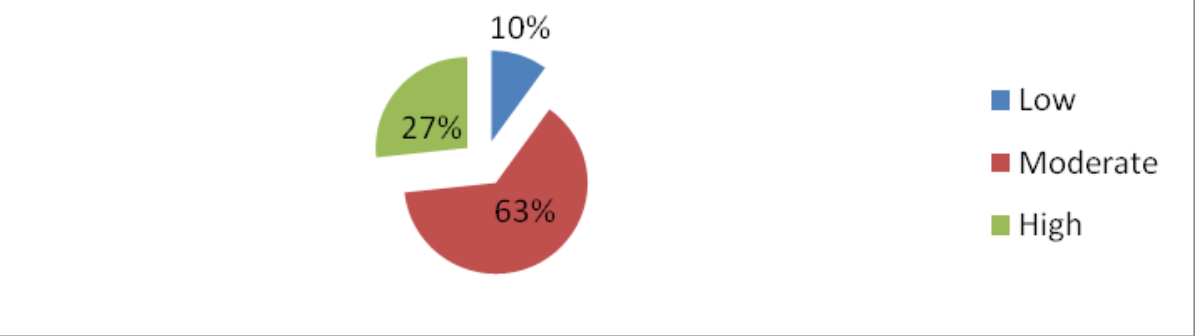

Figure 2

It was observed that science students had high level of anxiety as compared to art students. It was also observed during research that science side students feel more stressed due to heavy expectations from family and society. Its common people thinking and society leveled that if any children take science stream it means that they were intelligent and having 
extraordinary IO level. That point of view creates lots of pressure on students and sometimes they are not able to cope up with that expectation and committed suicide or having serious mental problems in their personality.

\section{SUMMARY AND CONCLUSIONS}

This study revealed that academic students suffer from high level of anxiety. Previous studies researchers found that many sources of anxiety among students such as exam anxiety, presentation stress, language anxiety, social and family anxiety. This study seems to be supportive that B.Sc. student had more stress in their lives while completing school than B.A students and it was mainly due to heavy lab work and class performance. By educating students, teachers can help the student's to fight test and performance stress in examination room. Teachers motivate students self-confidence and self-efficiency to combat all problematic situations in class, family and society. They also help in developing a positive attitude towards life.

\section{RECOMMENDATIONS}

- A comparative study can be undertaken between high, middle and low-income groups.

- A comparative study may be carried out in other varied locales i.e. rural areas, small towns and metropolitans.

\section{REFERENCES}

1. Huberty, T.J(2009).Test and performance anxiety. Principal Leadership, 10,12-16.Retrieved from http://www.nasponline.org/

2. Ahmed, W, Minnaert, A., Kuyper, H., \& van der Werf, G.(2011). Reciprocal relationships between math self-concept and math anxiety. Learning and Individual Differences,22,385-389.Retrieved from http://www journals.elsevier.com/learning-andindividual-differences

3. Bensoussan, 2012; Beauchemin,j.,Hutchins,T.L.,\& Patterson,F.(2008).Mindfulness meditation may lessen anxiety, promote social skills, and improve academic performance among adolescents with learning disabilities. Complementary Health Practice Review,13(1),34-45.doi:10.1177/1533210107311624

4. Swanson, S.,\& Howell, C.(1996). Test anxiety in adolescents with learning disabilities and behavior disorders. Exceptional Children, 62 (5), 389-389. Retrieved from http://journals.cec. Sped.org/ec/

5. Kumari, S. Ashwini, and N. Rajani. "Review of Academic Achievement and Influencing Factors." International Journal of Educational Science and Research (IJESR) 7.6, Dec 2017, 27-40

6. Venkataraman, S., and S. Manivannan. "Mental Depression of Higher Secondary Students." International Journal of Environment, Ecology, Family and Urban Studies (IJEEFUS) 8 (2018): 51-60.

7. Manivannan, S., and S. Venkataraman. "A Review on Studies Related to Anxiety of Higher Secondary Students." International Journal of Human Resource Management and Research (IJHRMR) 8.5, Oct 2018, 81-92 
